\title{
COMPENSATORY GROWTH IN OCEANIC LOGGERHEAD SEA TURTLES: RESPONSE TO A STOCHASTIC ENVIRONMENT
}

\author{
Karen A. Buorndal,,${ }^{1,4}$ Alan B. Bolten,,${ }^{1}$ Thomas Dellinger,${ }^{2}$ Cláudia Delgado, ${ }^{2}$ \\ AND Helen R. MARTins ${ }^{3}$ \\ ${ }^{1}$ Archie Carr Center for Sea Turtle Research and Department of Zoology, University of Florida, P.O. Box 118525, \\ Gainesville, Florida 32611 USA \\ ${ }^{2}$ Centro de Ciências Biológicas e Geológicas, Universidade da Madeira, Largo do Municipio, Colégio dos Jesuítas, \\ P-9000 Funchal, Madeira, Portugal \\ ${ }^{3}$ Departamento de Oceanografia e Pescas, Universidade dos Açores, PT-9901-862 Horta, Açores, Portugal
}

\begin{abstract}
Compensatory growth (CG, accelerated growth that may occur when an organism that has grown at a reduced rate as a result of suboptimal environmental conditions is exposed to better conditions) is considered an adaptation to variable environments. Although documented thoroughly under captive conditions, CG has rarely been studied in wild populations. In their first years of life, oceanic-stage loggerhead sea turtles (Caretta caretta) have relatively little control over their geographic position or movements and thus have an extremely stochastic lifestyle with great variation in food availability and temperature. This environmental variation results in variable growth rates. We evaluate somatic growth functions of oceanic-stage loggerheads from the eastern Atlantic based on skeletochronology that allowed us to assign age and cohort to each individual. We demonstrate $\mathrm{CG}$ in these turtles based on three different analytical approaches: changes in coefficients of variation in size-at-age, generalized additive model regression analyses of somatic growth, and linear regression of age-specific growth rates. As a result of $\mathrm{CG}$, variation in size-at-age in these juvenile loggerheads is substantially reduced. Thus, size is a better predictor of age than expected based on variation in growth rates. CG decreases with age, apparently as loggerheads gain greater control over their movements. In addition, we have evaluated for the first time in wild sea turtles the time-dependent nature of somatic growth by distinguishing among age, year, and cohort effects using a mixed longitudinal sampling design with assigned-age individuals. Age and year had significant effects on growth rates, but there was no significant cohort effect. Our results address critical gaps in knowledge of the demography of this endangered species.
\end{abstract}

Key words: age-year-cohort effects; Caretta caretta; compensatory growth; demography; marine turtle; skeletochronology; somatic growth; time-varying parameters.

\section{INTRODUCTION}

Compensatory growth (CG), or "catch-up" growth, occurs when an organism that has experienced reduced growth rates as a result of limited food resources or low temperatures (in ectotherms) is exposed to an improved nutritional or thermal environment (Wilson and Osbourn 1960, Hayward et al. 1997, Mangel, in press). After shifting to improved conditions, the organism grows at a more rapid rate than that exhibited by conspecifics of the same age that have enjoyed the better conditions throughout life. After a period of time in improved conditions, the organism that had been restricted may catch up to the size of the continuously well-fed conspecifics. CG has important implications for population dynamics (Nicieza and Metcalfe 1997, Mangel, in press) and demographic models (Whitledge et al. 1998). In populations in which individuals exhibit

Manuscript received 7 February 2002; revised 27 September 2002; accepted 30 September 2002. Corresponding Editor: R. J. Etter.

${ }^{4}$ E-mail: kab@zoology.ufl.edu
CG, size will be a better indicator of age, and variation will be less in the age of individuals undergoing sizedependent transitions, such as recruitment or reproductive maturity in many ectotherms. For example, CG decreased deviation from the optimal length at smolting in wild Atlantic salmon (Salmo salar) (Nicieza and Braña 1993). In populations with size-dependent mortality or foraging, CG will lessen variation in these parameters within age classes. However, there may be a cost to individuals that undergo CG; their future productivity and survivorship may be reduced (Metcalfe and Monaghan 2001). CG has been reported in plants, invertebrates, and vertebrates (Mangel, in press) and is considered an adaptation to a lifestyle with wide fluctuations in food availability (Broekhuizen et al. 1994).

During their first years of life, North Atlantic loggerhead sea turtles (Caretta caretta; see Plate 1) inhabit extremely stochastic environments. The duration and path of the journey undertaken by loggerhead hatchlings from western Atlantic nesting beaches to eastern 


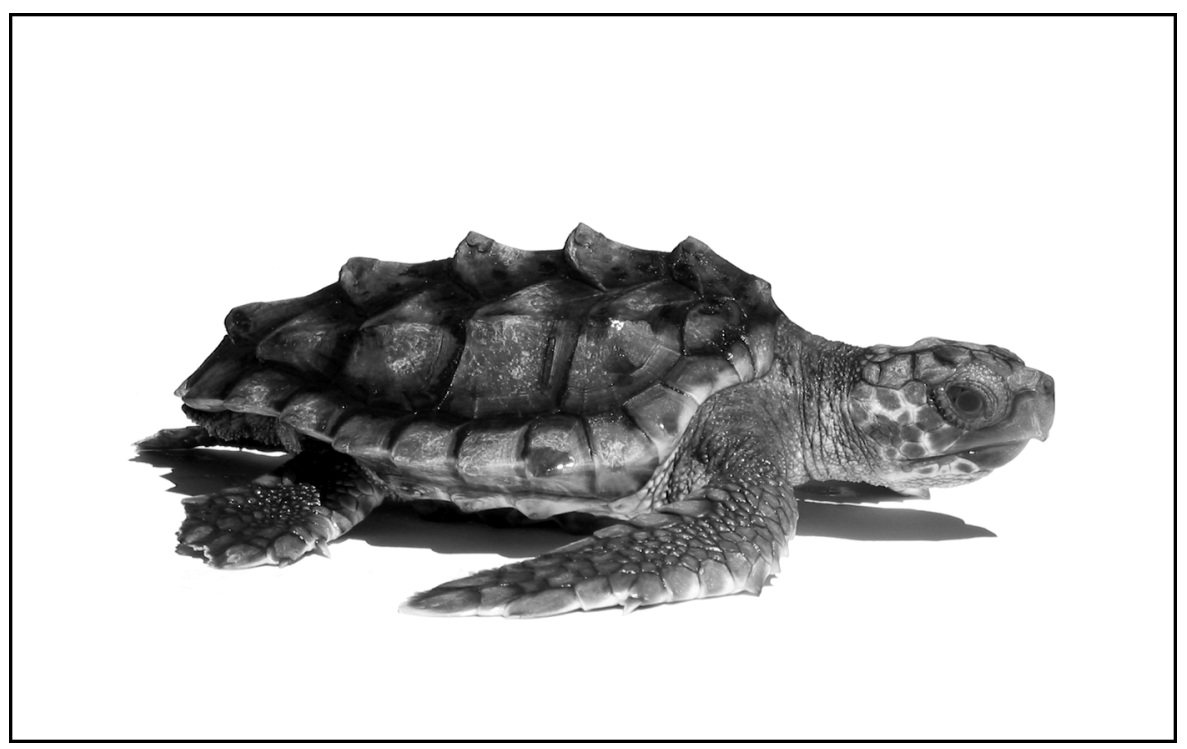

Plate 1. An oceanic-stage loggerhead with a curved carapace length of $17.3 \mathrm{~cm}$. The sharp projections on the vertebral scutes are characteristic of this life stage. Photograph by Skye White.

Atlantic oceanic foraging areas are determined largely by chance (Witherington 2002, Bolten, in press). Each year along the east coast of the United States, loggerhead hatchlings emerge from $>1500 \mathrm{~km}$ of nesting beaches from Florida to North Carolina between late June and early November. Thus, as hatchlings leave the beach and enter the ocean, they encounter habitats that vary greatly in temperature, wind, and current conditions, and distance to offshore currents. Hatchling loggerheads swim actively for the first $24 \mathrm{~h}$ after entering the ocean (Wyneken 1997) and maintain a straight-line course that will carry them away from shore (Salmon and Wyneken 1987, Witherington 1991). This "swimming frenzy" helps the hatchling traverse the inshore waters, reach offshore currents, and become incorporated into the North Atlantic Gyre. Loggerhead hatchlings can orient to the magnetic field of the Earth, and, if hatchlings are exposed to magnetic fields with inclination angles corresponding to either the northern or southern boundaries of the North Atlantic Gyre, they swim to the southeast or northeast, respectively-orientations that would tend to maintain their position within the Gyre (Lohmann et al. 2001, Lohmann and Lohmann, in press). However, the swimming strength and orientation abilities of loggerhead hatchlings are easily overwhelmed by waves, winds, and currents, and these forces largely determine the path that a hatchling follows. While crossing the Atlantic and in the first years of life in the waters around the Azores and Madeira, loggerheads are primarily surface-living "floatand-wait" predators (Bolten, in press). Because oceanic-stage loggerheads feed largely on epipelagic invertebrates with patchy distributions, this lifestage experiences alternating periods of food abundance and limitation (Bjorndal 1997, in press). Therefore, during their early years, loggerheads are exposed to a wide variety of water temperatures and food resources that would be expected to yield a wide range of growth rates.

This stochastic environment makes oceanic-stage loggerheads excellent candidates for CG. Most studies of CG have involved controlled studies in captive animals; few studies have evaluated CG in wild populations (Nicieza and Braña 1993, Whalen and LaBar 1998, Whitledge et al. 1998). Our study of growth in assigned-age oceanic loggerheads provided an opportunity to evaluate CG in this species in the wild. We have used skeletochronology to assign ages and estimate annual growth rates for loggerheads in oceanic habitats around the Azores and Madeira. Skeletochronology, or the use of incremental growth marks in vertebrate bones and hard structures to estimate age of individuals, has been used for many years to generate size-at-age curves in a variety of species (Castanet et al. 1993).

The loggerhead sea turtle is a long-lived, slow growing species that is listed as threatened or endangered throughout its global range (Hilton-Taylor 2000). Because of the great concern for the management and conservation of sea turtles, efforts have been made to develop effective management plans based on sound population models (Crowder et al. 1994, Crouse and Frazer 1995, Heppell et al. 1996, in press, Chaloupka, in press). Development of models is hampered by gaps in our knowledge of the biology of loggerheads (Heppell et al. 1999, in press) particularly in the early, oceanic life stage (National Research Council 1990). In addition, models of somatic growth in wild sea turtles have had to assume no significant age or cohort dependence because the longitudinal and mixed cross- 
sectional sampling designs of growth studies have precluded distinguishing among the time-dependent effects of age, year, and cohort (Chaloupka and Musick 1997; M. Y. Chaloupka, unpublished manuscript). However, growth is a time-varying function with three sources of temporal variation: age, year, and cohort (Hagen and Quinn 1991; M. Y. Chaloupka, unpublished manuscript).

Our retrospective analysis of growth in assigned-age individuals has allowed us to go beyond analyses of population-level patterns of growth and size-at-age in juvenile loggerheads to evaluate individual-level trajectories that create these patterns. We have assessed whether loggerheads respond to their stochastic environment and variable resource base by exhibiting CG and the extent to which CG moderates variation in sizeat-age in the oceanic lifestage. In addition, we have evaluated for the first time in wild sea turtles the timedependent nature of somatic growth by distinguishing among age, year, and cohort effects.

\section{Materials And Methods}

\section{Sample collection and processing}

We collected data from 44 loggerheads: 40 oceanicstage loggerheads from the waters surrounding the Azores $(n=9)$ and Madeira $(n=31)$ and 4 hatchlings from Cape Canaveral Air Force Station, Florida. Samples from Azores and Madeira were combined because they represent the same population, and Florida hatchlings are appropriate for this study because oceanicstage loggerheads in the Azores and Madeira are primarily derived from southeast U.S. nesting beaches (Bolten et al. 1998). No turtles were sacrificed for this study. Turtles from the Azores and Madeira were either stranded carcasses or dead from incidental capture in longline fisheries. The hatchlings were salvaged from a study of sex determination (Mrosovsky and Provancha 1992). Body size was measured as curved carapace length from anterior edge of the nuchal scute to the posterior notch at midline between the supracaudals $( \pm 0.1 \mathrm{~cm})$, and date of death was recorded or estimated for all turtles. One humerus was removed from each turtle and preserved in $70 \%$ ethanol. A cross section of bone was removed just distal to the deltopectoral crest (Zug et al. 1986), decalcified, embedded in paraffin, sectioned at $8-10 \mu \mathrm{m}$ thickness, and stained with Ehrlich's hematoxylin.

Stained sections were examined under a dissecting scope. Humerus radius was measured from the focus of the medullary cavity to the ventral edge of the bone perpendicular to the long axis of the medullary cavity, and distances from the focus to each growth mark (GM) were measured along the same line. GM were clearly visible along all four axes, but GM were most consistent along the ventral axis, as reported by Parham and Zug (1997). Measurements were made with Optimas 6 software (Optimas Corporation, Bothell, Washington,
USA). Precision of measurements was evaluated by repeating measurements for 10 turtles on successive days and calculating the absolute difference between pairs of repeated measures.

We obtained histological cross sections that could be evaluated for GM from 35 of the 40 oceanic-stage loggerheads. Sections from the other five turtles were damaged during processing and, because the location of cross sections along the longitudinal axis of the humerus affect the relationship of humerus radii to curved carapace length, additional sections would not provide comparable data. We could not assign a date of death (and thus cohort year) to 1 of the 35 oceanic-stage loggerheads. Because of the relatively young age of the loggerheads in our study, few GM had been lost as a result of remodeling of bone tissue at the inner or endocortical edge of the cortical bone as the medullary cavity expands during growth. Because of the consistency of GM radii among turtles, we could identify turtles that had lost GM to bone remodeling because the radius of the medullary cavity was greater than the radius of first and second year GM. We assigned two additional GM to one turtle and one additional GM to seven turtles; these GM were only used to assign age and cohort to individual turtles, not to calculate growth rates. We thus avoided use of GM loss correction protocols, which are problematic (Parham and Zug 1997). To determine the possible effect of error in our assignment of the nine GM lost from eight turtles, we deleted the eight turtles with remodeled GM from the data set and reran the analyses described below. These analyses yielded the same results and the same conclusions about compensatory growth.

\section{Sampling design and statistical modeling approach}

We modeled somatic growth statistically using general additive models (GAM). These regression models comprised an identity link, a robust quasi-likelihood error function, and cubic smoothing splines. The fit summary for all models includes an estimate of the contribution of each covariate to the overall model fit using $t$ ratio statistical inference and an estimate of the nonlinearity for each continuous covariate (nonparametric term) using a nonparametric $F$ ratio test. The use of general additive models in the analysis of growth rates is discussed in more detail in Chaloupka and Limpus (1997).

The main regression analysis had one response variable (absolute growth rate) and four potential growth covariates, of which three were continuous (initial size, initial age, and year) and one was a nominal factor (cohort). Initial size and initial age are the size and age at the beginning of the growth increment, respectively. To evaluate compensatory growth $(\mathrm{CG})$, the regression analysis was repeated with mean size (the mean of sizes at the beginning and end of the growth increment) replacing initial size. In organisms experiencing $\mathrm{CG}$, size at the beginning of a growth increment is a better pre- 
TABLE 1. Age-year-cohort data structure for analysis of effect of these time-varying parameters on growth in loggerhead sea turtles.

\begin{tabular}{crrrrrrrrrrr}
\hline \hline & \multicolumn{10}{c}{ Initial age (yr) } \\
\cline { 2 - 12 } Year & 0.7 & 1.7 & 2.7 & 3.7 & 4.7 & 5.7 & 6.7 & 7.7 & 8.7 & 9.7 & 10.7 \\
\hline 1987 & $\ldots$ & $\ldots$ & 1 & & & & & & & & \\
1988 & $\ldots$ & $\ldots$ & $\ldots$ & 1 & & & & & & & \\
1989 & 2 & $\ldots$ & $\ldots$ & $\ldots$ & 1 & & & & & & \\
1990 & 3 & 2 & $\ldots$ & $\ldots$ & $\ldots$ & 1 & & & & & \\
1991 & 4 & 3 & 2 & $\ldots$ & $\ldots$ & $\ldots$ & 1 & & & & \\
1992 & 5 & 4 & 3 & 2 & $\ldots$ & $\ldots$ & $\ldots$ & 1 & 1 & & \\
1993 & 6 & 5 & 4 & 3 & 2 & $\ldots$ & $\ldots$ & $\ldots$ & 1 & 1 & \\
1994 & 7 & 6 & 5 & 4 & 3 & 2 & $\ldots$ & $\ldots$ & $\ldots$ & $\ldots$ & 1 \\
1995 & 8 & 7 & 6 & 5 & 4 & 3 & 2 & $\ldots$ & $\ldots$ & $\ldots$ & $\ldots$ \\
1996 & 9 & 8 & 7 & 6 & 5 & 4 & 3 & 2 & $\ldots$ & $\ldots$ & $\ldots$ \\
1997 & 10 & 9 & 8 & 7 & 6 & 5 & 4 & 3 & 2 & 2 & $\ldots$ \\
1998 & 11 & 10 & 9 & 8 & 7 & 6 & 5 & 4 & 3 & 2 \\
\hline
\end{tabular}

Note: Initial age is the age at the beginning of the growth increment, year is the year of growth $(1987=1$ May 1987-30 April 1988), and each cell contains cohort number.

dictor of growth rate than mean size (for explanation, see Results).

We also evaluated CG by comparing the relationship of growth rate to initial size for initial ages from 0.7 to $4.7 \mathrm{yr}$. Within this age range the relationship between growth rate and initial size was linear, and the sample size of each year class was sufficient for analysis. If loggerheads in our study exhibited CG, the regression lines of the individual age classes should decline more steeply (that is, smaller turtles within an age class would grow faster) than that of the combined age classes. We compared slopes as described by Zar (1984: 292). To test for autocorrelation in the regression analysis of the combined age classes because multiple growth estimates were derived from individual turtles, we regressed the residuals of age ${ }_{i}$ against the residuals of age $\mathrm{e}_{i+1}$ for all individuals. The slope was not significantly different from $0(F=0.144$, df $=64, P=$ 0.706), giving no evidence of autocorrelation. To avoid using the same data when comparing slopes of individual age classes with the slopes of combined age classes, the data for the individual age class in each comparison were not included in the combined age class data. That is, the slope for age 0.7-yr turtles was compared against the slope for age 1.7-4.7 yr turtles.

The sampling design in this study was mixed longitudinal sampling, which allowed us to model growth as a time-varying process using an age-year-cohort approach (M. Y. Chaloupka, unpublished manuscript). For analysis of time-dependent effects, data were structured as shown in Table 1, in which columns are ages, rows are years, and diagonals are cohorts. Cohorts 18 corresponded to loggerheads that hatched in 1984 and 1988 through 1997, respectively. The regression analysis had one response variable (absolute growth rate) and three potential growth covariates, of which two were continuous (initial age and year) and one was a nominal factor (cohort).
All general additive regression analyses were repeated with the tails of year and age distributions (years 1987-1990, ages eight and above, or both) excluded to determine whether these changes significantly affected the models. These changes in the analyses had no effect on any of the models (Table $2 \mathrm{a}-\mathrm{c}$; analyses of deviance, $P>0.05$ ).

We used S-Plus software (S-Plus 2000 Professional Release 2, Insightful, Seattle, Washington, USA) for all statistical analyses. For all analyses, alpha $=0.05$.

\section{RESUlts \\ Growth marks}

Loggerheads in our study ranged from 4.5 to 59.2 $\mathrm{cm}$ curved carapace length (Fig. 1). All loggerheads other than the hatchlings $(n=35)$ exhibited growth marks (GM, Fig. 2), which we interpreted as representing periods of slow or no growth just prior to or after hatching (natal lines) or during annual periods of colder water temperatures. Mean precision of measurements of humerus radii was $0.0011 \mathrm{~mm}(\mathrm{SD}=$ 0.00017 ; repeated measures for 10 turtles), which is $0.04 \%$ of the mean of the radius measurements $(2.7624$ $\mathrm{mm}, n=185$, range $=0.4932-6.1481)$. Natal lines have been recorded from several reptile species (de Buffrénil and Castanet 2000) and would be expected in loggerheads because growth slows substantially before hatching and just after hatching as yolk stores are consumed (Ackerman 1981). We identified natal lines in eight of the smallest loggerheads. This identification of natal lines is supported because the mean radius from focus to designated natal lines in the eight loggerheads $(0.56 \mathrm{~mm}, \mathrm{SD}=0.01)$ was not significantly different ( $t$ test, $t=1.079$, df $=10, P=0.306$ ) from the mean humerus radius in hatchlings $(0.55 \mathrm{~mm}, \mathrm{SD}=0.03)$.

We interpret the GM other than natal lines as annual based on the following evidence. First, the GM were deposited at regular intervals as demonstrated by the 
TABLE 2. Summaries of general additive regression analyses for loggerhead sea turtles (identity link, robust quasi-likelihood error function, cubic smoothing splines).

\begin{tabular}{|c|c|c|c|c|c|c|c|}
\hline \multirow[b]{2}{*}{ Parameter } & \multirow[b]{2}{*}{ Estimate } & \multirow[b]{2}{*}{ ASE } & \multirow[b]{2}{*}{$t$ ratio } & \multirow[b]{2}{*}{$\operatorname{Prob}(t)$} & \multicolumn{3}{|c|}{$\begin{array}{l}\text { Nonlinear effects } \\
\text { (nonparametric) }\end{array}$} \\
\hline & & & & & $\mathrm{df}$ & $F$ & $P$ \\
\hline \multicolumn{8}{|c|}{ a) Size-at-age model $\dagger$} \\
\hline Constant & 7.2909 & 0.1896 & 38.452 & & & & \\
\hline Age & 5.8829 & 0.0687 & 85.575 & $<0.001$ & 7 & 28.412 & $<0.001$ \\
\hline \multicolumn{8}{|c|}{ b) Somatic growth model with initial size $\ddagger$} \\
\hline Constant & -292.69 & 105.64 & -2.771 & & & & \\
\hline Initial size & -0.3428 & 0.0599 & -5.726 & $<0.001$ & 2.9 & 0.390 & 0.756 \\
\hline Initial age & 1.4685 & 0.3047 & 4.820 & $<0.001$ & 3.0 & 4.908 & 0.003 \\
\hline Year & 0.1516 & 0.0530 & 2.862 & $<0.01$ & 3.0 & 2.420 & 0.072 \\
\hline \multicolumn{8}{|c|}{ c) Somatic growth model with mean size $\S$} \\
\hline Constant & -329.86 & 120.29 & -2.742 & & & & \\
\hline Mean size & 0.0112 & 0.0692 & 0.162 & NS & 3.0 & 2.850 & 0.042 \\
\hline Initial age & -0.2623 & 0.3455 & -0.759 & NS & 3.0 & 0.352 & 0.786 \\
\hline Year & 0.1683 & 0.0604 & 2.787 & $<0.01$ & 3.0 & 2.747 & 0.048 \\
\hline \multicolumn{8}{|c|}{ d) Time varying somatic growth model $\|$} \\
\hline Constant & -319.25 & 96.636 & -3.304 & & & & \\
\hline Initial age & -0.2619 & 0.0571 & -4.587 & $<0.001$ & 3.0 & 1.596 & 0.204 \\
\hline Year & 0.1631 & 0.0485 & 3.365 & $<0.002$ & 3.0 & 4.608 & 0.007 \\
\hline
\end{tabular}

Notes: ASE is asymptotic standard error, initial size is curved carapace length at the beginning of the growth increment, and mean size is the mean of the curved carapace lengths at the beginning and end of the growth increment. Probabilities $(P)$ reported for $F$ values are based on nonparametric df and residual deviance df. A significant nonparametric $F$ means that the covariate was nonlinear. If the $t$ test for a covariate is not significant (NS) then the nonparametric $F$ test for nonlinearity is irrelevant. $R^{2}=$ (null deviance - residual deviance)/null deviance.

$\dagger$ Null deviance $=919.33$, null $\mathrm{df}=149$, residual deviance $=21.74$, residual $\mathrm{df}=141$, quasi-likelihood dispersion parameter $=0.15, R^{2}=0.976$.

$\ddagger$ Null deviance $=340.97$, null $\mathrm{df}=106$, residual deviance $=194.34$, residual $\mathrm{df}=94.2$, quasi-likelihood dispersion parameter $=1.67, R^{2}=0.430$.

$\S$ Null deviance $=340.97$, null $\mathrm{df}=106$, residual deviance $=235.17$, residual $\mathrm{df}=94.1$, quasi-likelihood dispersion parameter $=2.15, R^{2}=0.310$.

$\|$ Null deviance $=99.17$, null $\mathrm{df}=53$, residual deviance $=48.14$, residual $\mathrm{df}=45.1$, quasi-likelihood dispersion parameter $=0.98, R^{2}=0.515$.

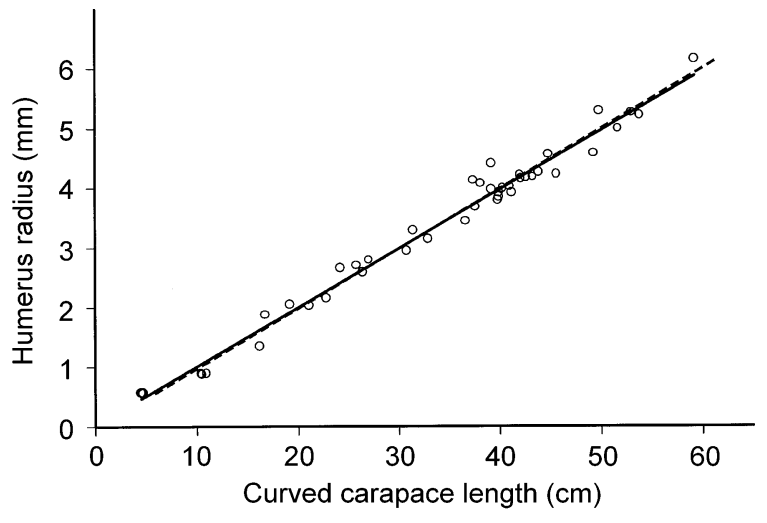

FIG. 1. Relationship of curved carapace length (CCL) and ventral humerus radius (HR) at time of death for 44 loggerheads (four hatchlings from Florida and 40 oceanic-stage loggerheads from Azores and Madeira). The relationship between CCL and HR is symmetrical: solid line is linear regression with HR as dependent variable $\left(P<0.001, R^{2}=\right.$ 0.984 , df $=42)$; dashed line is linear regression with CCL as dependent variable $\left(P<0.001, R^{2}=0.984, \mathrm{df}=42\right)$. significant positive relationship between the curved carapace length and the number of GM for the loggerheads in our study that had at least one annual GM (linear regression, df $=27, P<0.0001, R^{2}=0.925$ ). The regression equation is

$$
\mathrm{GM}=0.2002(\mathrm{CCL})-2.6562
$$

where GM is number of GM and CCL is curved carapace length $(\mathrm{cm})$. If GM were not deposited at regular intervals, there would be greater variance in the number of GM with increasing size (age) as a result of an accumulation of spurious additions or omissions over time. Inspection of the residuals indicated that there was no increase in variance.

Second, we demonstrate that GM are deposited annually based on recapture of tagged oceanic-stage Atlantic loggerheads. Of the recapture data reported in Bjorndal et al. (2000b), capture and recapture sizes of six of the loggerheads $(19.3-52.0 \mathrm{~cm})$ spanned the size range of the turtles upon which Eq. 1 was based. The duration of the interval between capture and recapture for each of the six turtles was accurately predicted by Eq. 1 if each GM represents one year. The predicted number of GM that would have been deposited during the capture-recapture interval equaled the number of 


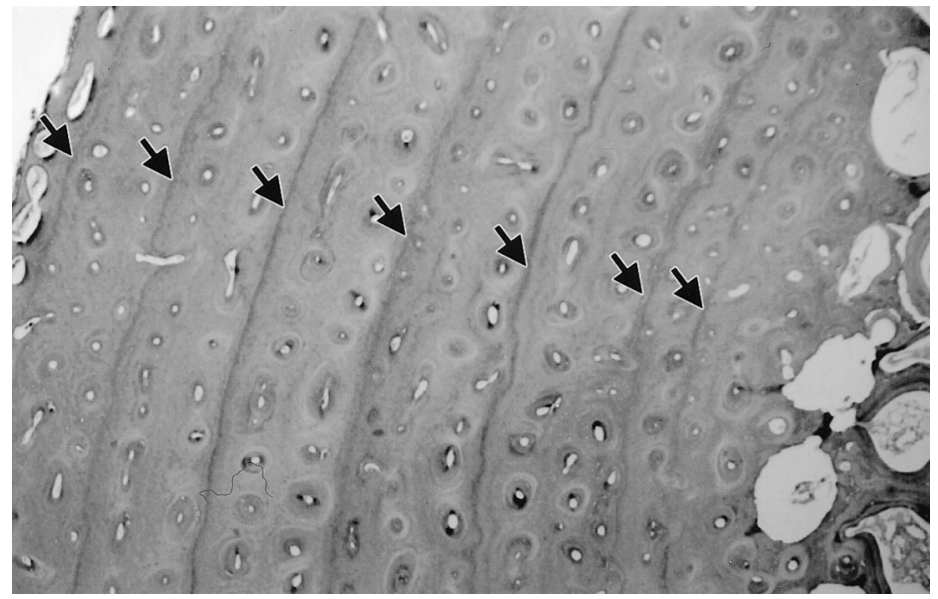

FIG. 2. A cross section of humerus stained with Ehrlich's hematoxylin showing seven annual growth marks (indicated by arrows). Ventral periosteal surface is on the left, and the medullary cavity is on the right.

complete years in the actual duration (range 2-5 yr). This demonstrates that GM are annual.

Further support for annual GM is provided by a previous study (Bjorndal et al. 2000b) in which we used length-frequency analyses to assign ages to size classes of oceanic-stage loggerheads in the Azores. That study yielded a size-at-age function similar to that of this study when GM are assigned to annual increments (Fig. $3)$. Thus, two completely different analytical approaches (skeletochronology and length-frequency) based on two nonoverlapping data sets have assigned the same ages to similar size ranges of turtles in this population.

Finally, the thermal environment of loggerheads in our study would be expected to yield seasonal changes in growth rates and thus annual GM. Loggerheads in our study are primarily surface living in a seasonal habitat with a marked annual temperature cycle. Surface water temperature varies from $\sim 16^{\circ} \mathrm{C}$ in winter to $\sim 25^{\circ} \mathrm{C}$ in summer (M. Alves, unpublished data). Loggerheads (summer residents in Chesapeake Bay, Virginia) in neritic habitats over the same range of lati- tudes and water temperatures as the turtles in our study have been shown to deposit annual growth marks (Klinger and Musick 1992, Coles et al. 2001). A temperature of $16^{\circ} \mathrm{C}$ is the coldest generally encountered by Chesapeake Bay loggerheads (Keinath et al. 1987, Musick and Limpus 1997).

\section{Size-at-age}

We estimated the size of each loggerhead at each annual GM using the constant proportional relationship between humerus radius (HR) and curved carapace length (CCL) over the size range in our study (Fig. 1, $P<0.001, R^{2}=0.984$, df $=42$ ) with the equation

$$
\mathrm{CCL}=(\mathrm{HR}-0.0191) / 0.0989 .
$$

Ricker (1992) cautioned that the relationship between body length and size of the skeletal element must be symmetrical, a condition met in our study (Fig. 1). In our estimates, we assume that the relationship between somatic and skeletal growth rates does not vary over

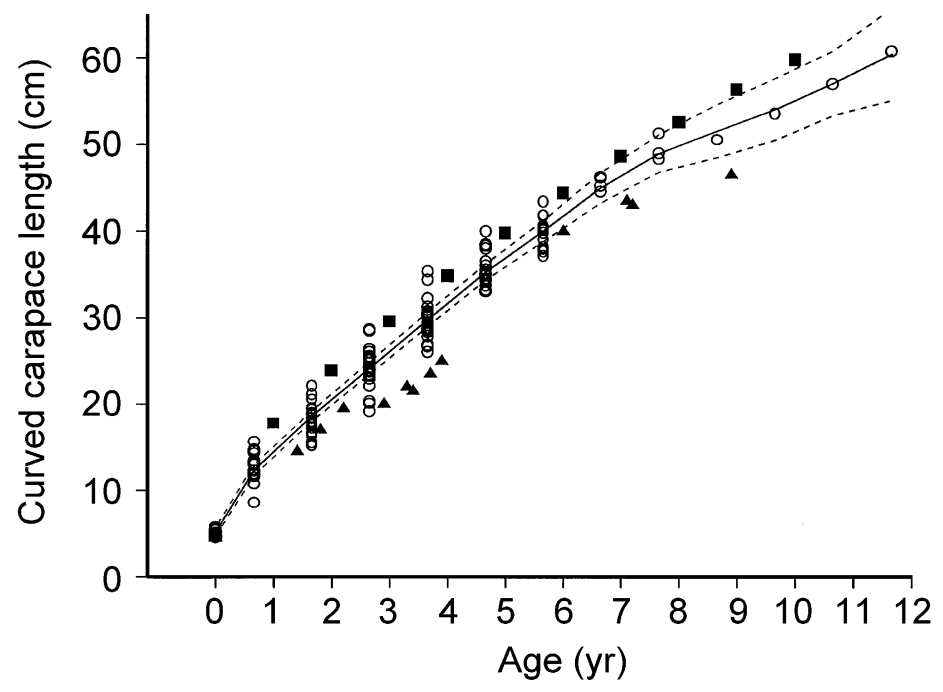

FIG. 3. Size-at-age function for Atlantic oceanic-stage loggerheads based on curved carapace lengths measured for four hatchlings (age $=0$ ) and curved carapace lengths estimated from humerus radii measured from focus to natal lines $($ age $=0)$ and to annual growth marks using Eq. 2 ( $n=146$ size-at-age values for 35 oceanic-stage loggerheads). The solid line is the cubic smoothing spline $(\mathrm{df}=8$, Table $2 \mathrm{a})$; dashed lines indicate $\pm 2 \mathrm{SE}$; open circles are data from this study; solid squares are estimates for the same population based on length-frequency analyses (Bjorndal et al. 2000b); solid triangles are estimates for oceanic-stage loggerheads in the Pacific (Zug et al. 1995). 
time; this assumption should be tested (Chaloupka and Musick 1997).

To assign ages to each of the annual GM, the age of the turtle at the first GM must be estimated. The midpoint in the emergence of loggerhead hatchlings from Florida nesting beaches is approximately 1 September (Bjorndal et al. 2000b), and if we assume that the first annual GM is laid down during the first winter, the loggerhead would be $<1$ year old. The size of loggerheads at the first annual GM is $12.6 \pm 1.7 \mathrm{~cm}$ (mean $\pm 1 \mathrm{SD}, n=21)$, and the mean size of hatchlings is $4.7 \mathrm{~cm}$ (Bjorndal et al. 2000 b). Based on sizes of the smallest stranded loggerheads in the Azores and growth rates of posthatchlings off the coast of Florida (B.E. Witherington, personal communication), Bjorndal et al. $(2000 b)$ estimated that loggerheads grow an average of $1 \mathrm{~cm} / \mathrm{mo}$ during their first months of life. A growth rate of $1 \mathrm{~cm} / \mathrm{mo}$ yielded an age of $8 \mathrm{mo}$ (or $0.7 \mathrm{yr}$ with time of hatching $=$ age 0 ) at the first GM. Therefore, we assigned 1 May as the first day of the growth interval year.

Ages (0, $0.7 \mathrm{yr}, 1.7 \mathrm{yr}$, and so on) were assigned to each size value estimated from each GM including natal lines ( $n=150$ including size of 4 hatchlings). Size and age were significantly related $(P<0.001$; Table 2a; Fig. 3), with age accounting for most of the variation in size $\left(R^{2}=0.976\right.$; Table $\left.2 \mathrm{a}\right)$. Data beyond $7.7 \mathrm{yr}$ are based on a single turtle and should be viewed with caution. The results did not change significantly when the data for $>7.7 \mathrm{yr}$ were omitted (analysis of deviance, df $=4, P \sim 0.996)$.

\section{Somatic growth models: compensatory growth and age-year-cohort effects}

We calculated 107 annual growth increments (1-9 increments per turtle) from increases in estimated curved carapace length between successive annual GM (Fig. 1) for 28 turtles of assigned age and cohort during the years 1987-1999. These 28 turtles had at least two annual GM so that a growth increment could be calculated. Growth rates varied from 2.2 to $11.0 \mathrm{~cm} / \mathrm{yr}$ with a mean of $5.4 \mathrm{~cm} / \mathrm{yr}(\mathrm{SD}=1.8)$ and a median of $5.4 \mathrm{~cm} / \mathrm{yr}$.

The general additive regression analysis with one response variable (absolute growth rate) and four potential growth covariates (initial size, initial age, year, and cohort) indicated that cohort effect was not significant. When the analysis was repeated, omitting cohort as a covariate, the resulting model (Table $2 b$ ) was not significantly different from the original model (analysis of deviance, df $=9, P \sim 0.32$ ). Initial size, initial age, and year had significant effects on growth and accounted for $43 \%$ of the variation in growth rates (Table 2b). To enhance evaluation of the size-specific and age-specific growth functions, cubic spline smooths were plotted on uncentered growth rate scales; error bands cannot be plotted on the uncentered scales (Fig. 4). Both growth functions are monotonic. Data
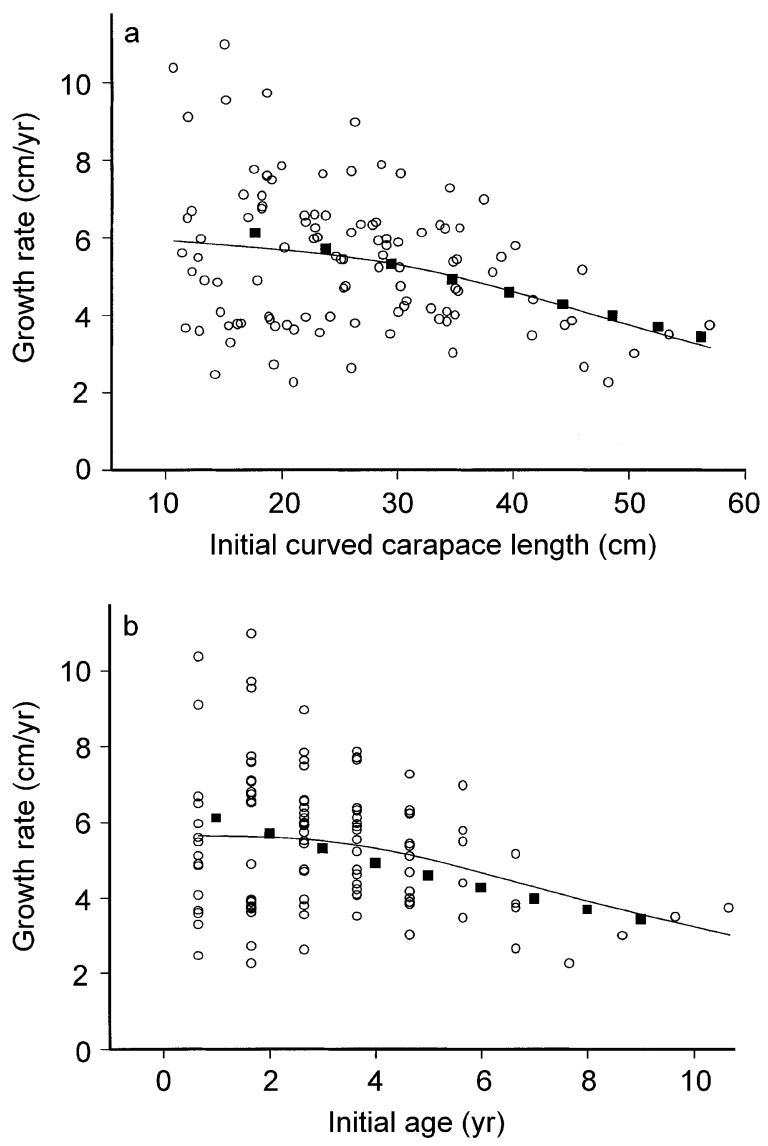

FIG. 4. The (a) size-specific and (b) age-specific growth rate functions for Atlantic oceanic-stage loggerheads $(n=$ 107 growth increments for 28 turtles). Initial curved carapace length and initial age are the size and age at the beginning of the growth increment, respectively. Solid lines are cubic smoothing splines ( $\mathrm{df}=3$ ) of fitted values from general additive regression analysis (Table $2 b$ ); open circles are data from this study; solid squares are estimates for the same population based on length-frequency analyses (Bjorndal et al. $2000 b)$.

for initial size $>48 \mathrm{~cm}$ and initial age $>7 \mathrm{yr}$ are based on a single turtle and should be viewed with caution. However, repeating the analysis without those data did not change the model significantly (analysis of deviance, $\mathrm{df}=10, P \sim 0.42$ ) or the shape of the splines for size $<48 \mathrm{~cm}$ or age $<7 \mathrm{yr}$.

The substantial variation in growth rates reported here (Fig. 4) is consistent with the great variation in food resources and temperatures experienced by young oceanic-stage loggerheads. The variation does not reflect genetic differences among individuals in the capacity for growth because changes in growth rates exhibited by individual turtles between successive annual growth increments are quite large (Fig. 5a). For example, the turtle with the most rapid growth in the 0.7yr age class exhibited the slowest growth rate in the 1.7-yr age class. Nor does the variation in growth rates simply reflect annual environmental variation (Fig. 5b). 

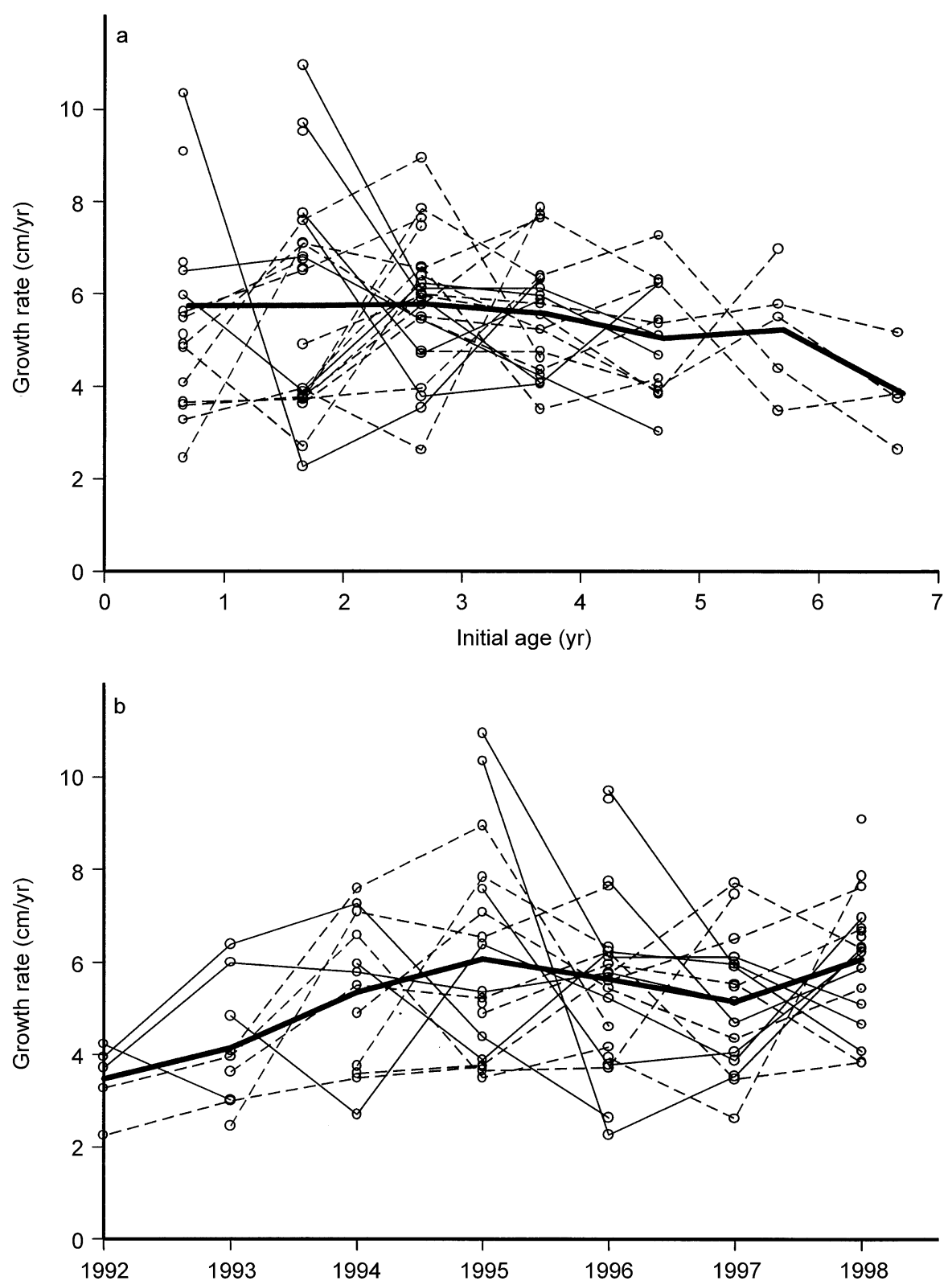

FIG. 5. (a) The trajectories of age-specific growth rates for individual loggerheads. The solid thick line is mean growth rate at each age; solid thin lines are individuals whose first measured growth rate was at age 0.7 or $1.7 \mathrm{yr}$ and above the mean; dashed lines are individuals whose first measured growth rate was at age 0.7 or $1.7 \mathrm{yr}$ and below the mean. Note that at successive ages, most individuals exhibit growth rate inversions; successive growth rates fall above and below the mean. (b) The trajectories of year-specific growth rates for individual loggerheads. The solid thick line is mean growth rate for each year; solid thin lines are individuals whose first measured growth rate was above the mean; dashed lines are individuals whose first measured growth rate was below the mean.

The variable growth rates would not be expected to yield the relatively low variation in size-at-age (Fig. 3 ) or decreasing coefficients of variation in size for each age class (based on the 16 turtles that lived to at least an age of $4.7 \mathrm{yr}$ to correct for any size-biased mortality; Table 3). Trajectories of size-at-age for individuals reveal how the population pattern of relatively low variation in size-at-age is maintained (Fig.
6). The annual variation in the individual growth-rate trajectories (Fig. 5a) caused the individual size-at-age trajectories to fluctuate above and below the size-atage curve for the population (Fig. 6), resulting in reduced variation in size-at-age. Of the turtles with at least two size-at-age values, the trajectories of only three turtles were completely above or below the smooth. 
TABLE 3. Coefficients of variation (CV) for initial curved carapace length in each age group for the 16 turtles that were at least 4.7 years of age at time of death to correct for possible size-biased mortality.

\begin{tabular}{ccc}
\hline \hline & \multicolumn{2}{c}{ Turtles at least 4.7 years of age } \\
\cline { 2 - 3 } Age (yr) & $n$ & $\mathrm{CV}$ \\
\hline 0.7 & 9 & 11.4 \\
1.7 & 15 & 8.8 \\
2.7 & 16 & 7.1 \\
3.7 & 16 & 7.2 \\
4.7 & 16 & 5.5 \\
5.7 & 13 & 4.6 \\
6.7 & 5 & 1.8 \\
7.7 & 4 & 2.6 \\
\hline
\end{tabular}

Note: $n=$ sample size.

Results of our analyses indicate that CG occurs in oceanic-stage loggerheads. In organisms exhibiting CG, for a given age class, initial size for a growth interval is a better predictor of growth rate than is mean size because individuals that are smaller at the beginning of the growth increment grow faster. By the time mean size is attained, because of faster growth, smaller individuals will have caught up with, or may even have surpassed, the individuals that were larger at the beginning of the growth interval, and thus mean size will not be as good a predictor of growth rate. Our results conform to this pattern. Initial size was a significant covariate in our growth model (Table 2b), but when mean size was substituted for initial size in the analysis, the model changed substantially, and mean size was not a significant covariate (Table $2 \mathrm{c}$ ). The difference in the relationships between growth and initial size or mean size is illustrated in Fig. 7 (covariate function plots centered on the response scale to ensure valid 95\% confidence bands [Hastie and Tibshirani 1990]).

Further evidence of CG is that the decline of growth rates with increasing initial size within an age class is greater than for age classes combined, particularly at young ages. For the combined age classes (0.7-4.7 yr), there is a significant decline in growth rate with increasing size (linear regression, $P=0.042$; Fig. 8). However, for initial age classes of 0.7 and $1.7 \mathrm{yr}$, the declines were significantly steeper than those of the combined age classes (for $0.7 \mathrm{yr}, P<0.001$, combined did not include 0.7-yr turtles to avoid using the same data in the two regressions; and for $1.7 \mathrm{yr}, P<0.01$, combined did not include 1.7-yr turtles). When we replaced initial size with mean size in the linear regression analyses, no slope was significantly different from 0 , and the slopes of the individual ages were not significantly different from the slopes of the combined age classes. Thus, loggerheads apparently compensate for the great variation in resources or ambient temperatures in early years through $\mathrm{CG}$, with the result that the variation in size-at-age decreases with age (Table 3$)$.
We distinguished among age, year, and cohort effects to evaluate the time-dependent nature of somatic growth. The analysis of time-varying covariates (age, year, and cohort; Table 1) indicated that cohort was not significant. Repeating the analysis without cohort yielded a model that was not significantly different from the original (analysis of deviance, $\mathrm{df}=9, P \sim$ 0.20 ); year and age were significant covariates, and the model accounted for $51.5 \%$ of the variation in growth rates (Table $2 \mathrm{~d}$ ).

\section{DisCUSSION}

\section{Size-at-age and duration of the oceanic stage}

Few studies have evaluated growth in oceanic loggerheads. The size-at-age function in our study (Fig. 3) falls slightly lower than earlier estimates for Azores loggerheads based on length-frequency analyses (Bjorndal et al. 2000b) and slightly higher than the estimates for oceanic-stage loggerheads in the Pacific Ocean (Zug et al. 1995).

Loggerhead hatchlings that emerge from nesting beaches in the southeastern United States spend their first years of life in oceanic habitats in the eastern Atlantic before they recruit to neritic habitats in the western Atlantic over a size range of 46-64 cm curved carapace length (Bolten et al. 1993, Bjorndal et al. $2000 \mathrm{~b}$ ). Does this wide size range at recruitment represent a narrow age range of individuals that have attained a wide range of sizes, or is size a relatively good indicator of age and loggerheads recruit to neritic habitats at a relatively wide range of ages? Our study supports the latter.

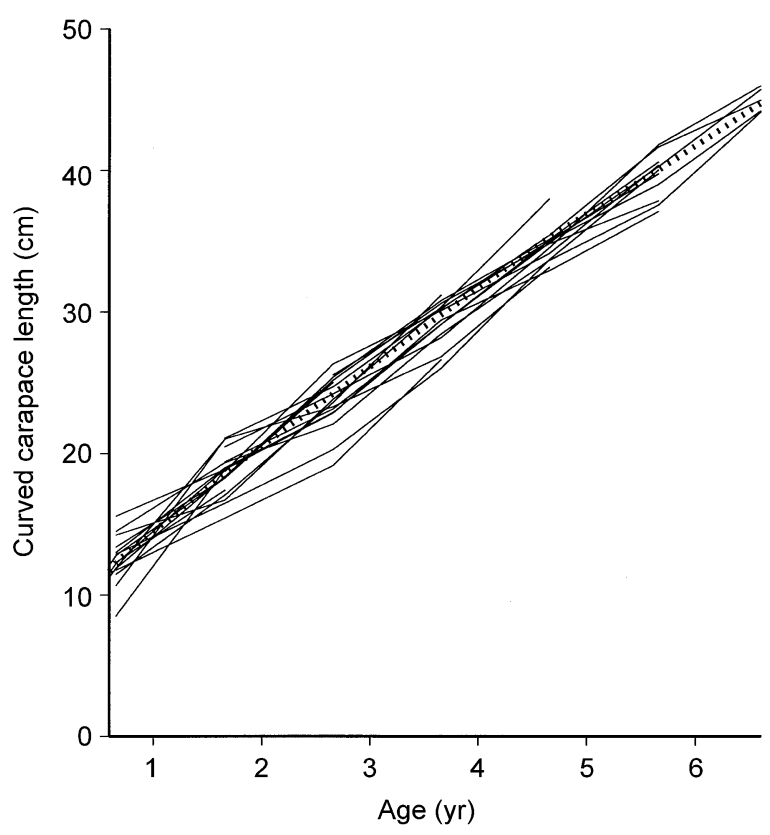

FIG. 6. Trajectories of size-at-age for individual loggerheads (solid lines). The dashed line is smooth from Fig. 3. 

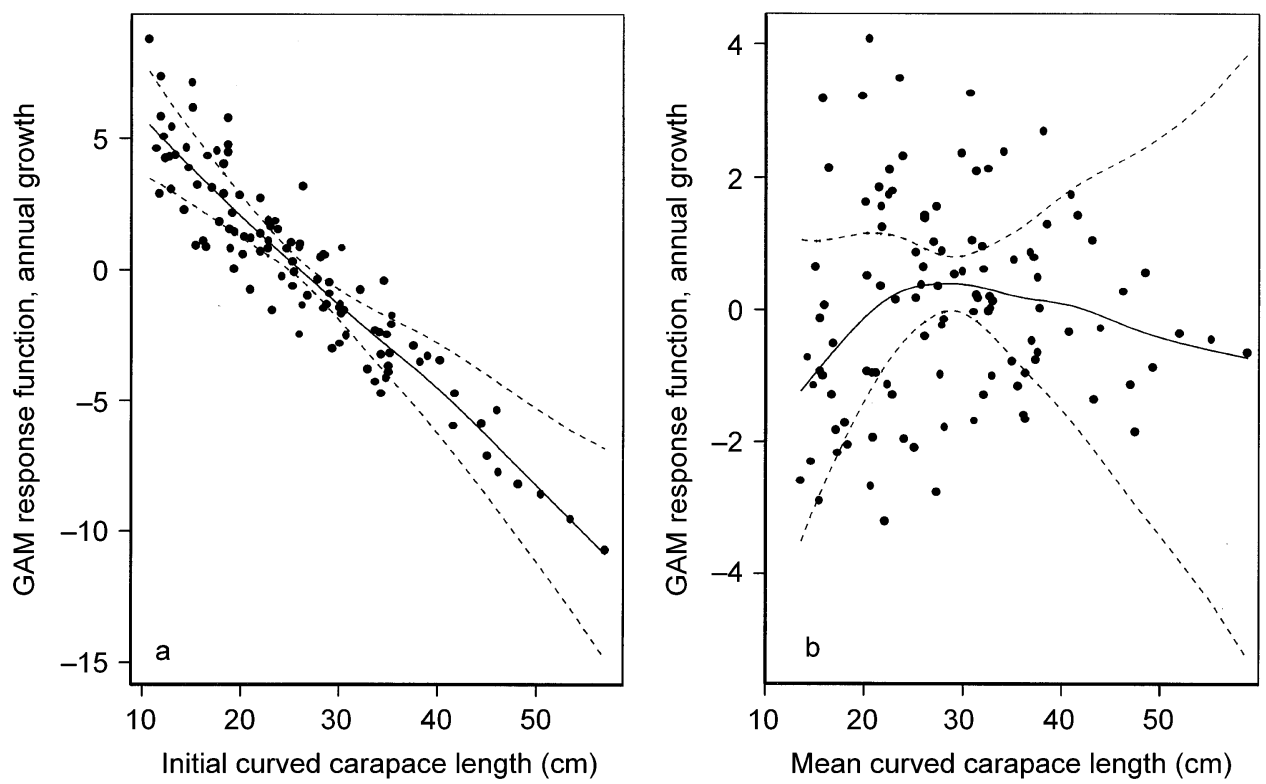

FIG. 7. Graphical summaries of general additive regression analyses of growth covariates of (a) initial size and (b) mean size. The response variable (annual growth rate) is shown on the $y$-axis as a centered smoothed function scale to ensure valid pointwise 95\% confidence bands. The solid lines are the cubic smoothing spline fits for each covariate conditioned on all other covariates in the analyses (Table 2b,c). Dashed lines are pointwise $95 \%$ confidence lines around the fits. Solid circles are residuals.

Bjorndal et al. (2000b) estimated the duration of the oceanic stage in Atlantic loggerheads to range from 6.5 yr (for turtles that recruited to neritic habitats at 46$\mathrm{cm}$ curved carapace length) to $11.5 \mathrm{yr}$ (for turtles that recruited at $64 \mathrm{~cm}$ ). From the present study, we estimate a duration of $7.0 \mathrm{yr}$ for loggerheads at $46 \mathrm{~cm}$. This longer estimate (by $0.5 \mathrm{yr}$ ) is not unexpected. Bjorndal et al. (2000b) stated that more data for turtles $<2 \mathrm{yr}$ old, which our present study provides, would improve the size-at-age model from the length-frequency analyses and probably lengthen the duration estimates. We cannot reevaluate the $11.5-\mathrm{yr}$ estimate for $64-\mathrm{cm} \mathrm{log}$ gerheads because that size is beyond the size range of our present study.

\section{Time-dependent growth rates: age-year-cohort effects}

A better understanding of the time-dependent nature of growth rates is attained if age, cohort, and year effects can be distinguished (M. Y. Chaloupka, unpublished manuscript). Previous studies of time effects on growth rates in wild sea turtles have confounded cohort effects (largely genetic or density dependent) with year effects (largely environmental) because either the ages of the turtles were not known or the authors of studies with assigned-age animals did not evaluate age, year, and cohort effects on somatic growth (Chaloupka and Musick 1997).

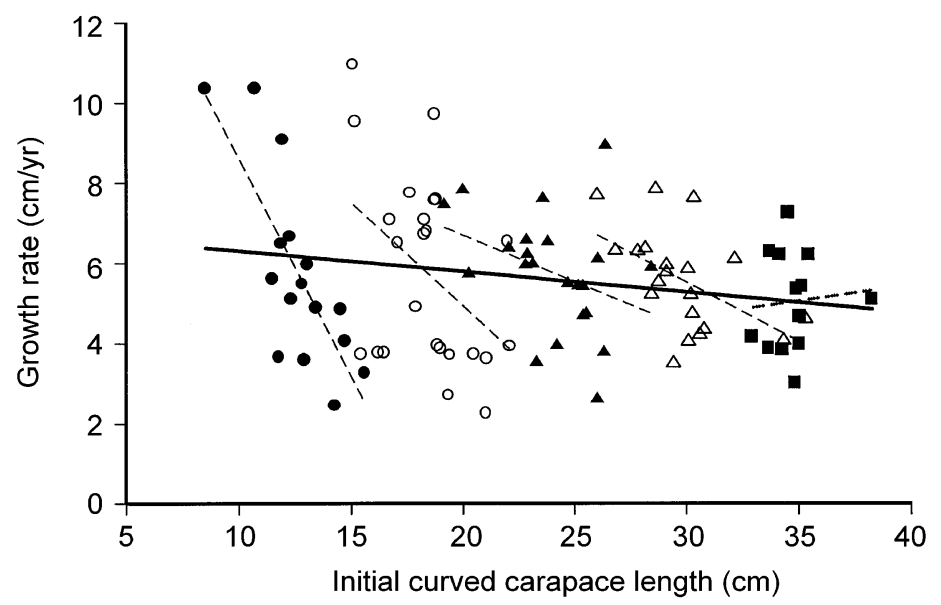

FIG. 8. Relationship of annual growth rate and initial curved carapace length for oceanicstage loggerheads with initial ages of $0.7,1.7$, 2.7, 3.7, and 4.7 yr. Symbols vary with initial age class: solid circles, $0.7 \mathrm{yr}$; open circles, 1.7 yr; solid triangles, $2.7 \mathrm{yr}$; open triangles, 3.7 yr; solid squares, 4.7 yr. The solid line is the regression line for combined age classes; dashed lines are regression lines for each age class. Slopes of regressions for combined ages, age 0.7 , age 1.7 , and age 3.7 are significantly different from $0(P<0.05)$. The slope of age 0.7 is significantly different from the slope of the combined age classes excluding age class 0.7 , and the slope of age 1.7 is significantly different from the slope of the combined age classes excluding age class $1.7(P<0.001$ and $P<0.01$, respectively). 
Year had a significant effect in our original somatic growth model (Table $2 b$ ), but year was confounded with cohort in that analysis. Because we can assign age and cohort to each growth increment, we were able to distinguish between year and cohort effects in our ageyear-cohort model. Of the time-dependent covariates in our study, both age and year had a significant effect on growth (Table 2d), but cohort effect was not significant. Lack of a significant cohort effect may be attributed to the highly variable lifestyle of oceanic loggerheads and to the different source rookeries that contribute to the oceanic population. The great variation in ambient temperatures and quantity of food resources experienced by individuals within each cohort during each year may well overwhelm any cohort effect.

\section{Compensatory growth}

Oceanic-stage loggerheads exhibit compensatory growth (CG) apparently in response to their stochastic environment in which food resources and temperature regimes vary greatly. As a result of $\mathrm{CG}$, variation in size-at-age is less than would be expected from the great variation in age-specific growth rates. The differences in possible interpretations underscore the importance of evaluating size-specific and age-specific growth rates in addition to size-at-age (Bjorndal et al. $2000 a$ ). Growth rate inversions between consecutive growth increments in individuals, such as those demonstrated by loggerheads in our study (Fig. 5a), have been noted in other species experiencing $\mathrm{CG}$ and result in reduced variation in size-at-age (Nicieza and Braña 1993, Nicieza and Metcalfe 1997).

Population models for Atlantic loggerheads have, of necessity, been stage-based models with stages defined largely by body size (Heppell et al., in press) because age cannot be readily determined in loggerheads. CG, as a mechanism by which variation in size-at-age is decreased, has important implications for these models. Because Atlantic loggerheads exhibit CG, size is a better indicator of age, ranges of age within the size-based stages are decreased, and size-specific parameters, such as mortality, are relatively good approximations of agespecific parameters.

Food availability early in life can have a disproportionate effect on an individual's later growth trajectory; this phenomenon has been reported in a number of species and has been termed the "silver-spoon" effect (Grafen 1988). The extensive variation in growth rate within individuals (Fig. 5a) indicates that, although individual loggerheads may have very different levels of food resources early in life, they did not exhibit a silverspoon effect. In a 13-year study of somatic growth in water pythons (Liasis fuscus), Madsen and Shine (2000) reported that the snakes exhibited a silver-spoon effect because the python cohorts that hatched in years when prey were abundant grew more rapidly throughout the study than did those that hatched in years when prey were rare. Madsen and Shine (2000) suggested that this effect may be widespread in organisms.

The extent of CG declines with size in oceanic-stage loggerheads as shown by the decreasing effect of initial size on growth rate with age (Fig. 8). This decline in CG corresponds to the period when loggerheads gain increasing control over their movements and geographic position. A $2.7-y r$ loggerhead ( $\sim 25 \mathrm{~cm}$ curved carapace length) has substantially increased swimming strength and diving capacities compared to younger turtles and thus may well have greater control over the temperature regimes and food resources that it experiences. Such decreased environmental variation would lessen the need for, and occurrence of, CG.

We cannot assess the mechanisms for CG in loggerheads from our study. CG often results from increased food intake, but can result from increased efficiency of conversion of ingested food to body tissue or from both mechanisms (Wilson and Osbourn 1960, Hayward et al. 1997, Nicieza and Metcalfe 1997). The occurrence of CG in loggerheads therefore suggests that loggerheads are capable of either increasing intake or increasing efficiency of food conversion to compensate for periods of low food availability. In an earlier study (McCauley and Bjorndal 1999), posthatchling loggerheads did not increase intake to compensate for diets with diluted nutrient concentrations, but there was a trend for the ability to increase intake to develop with age. Studies underway (A. McCombe, K. A. Bjorndal, and A. B. Bolten, unpublished data) on CG under controlled conditions in two species of turtles, the freshwater turtle Trachemys scripta and the sea turtle Chelonia mydas, will yield insights on the mechanisms of CG in turtles.

Compensatory growth is known to occur in plants, invertebrates, and vertebrates (Mangel, in press), and is considered an adaptation to a lifestyle with widely fluctuating food resources (Broekhuizen et al. 1994). The lifestyle of oceanic loggerheads (float-and-wait predators that may well go through alternating periods of feast and famine) fits that pattern. The occurrence of CG, however, may have negative ramifications. Studies in a variety of species have shown that animals that have undergone CG may incur a variety of costs over a range of time scales (Metcalfe and Monaghan 2001). Parameters that have been shown to be negatively affected include survival, energy reserves, body size, and reproductive success; these negative effects may not occur until long after the period of CG (Metcalfe and Monaghan 2001). Further studies of the extent and mechanisms of CG in sea turtles are needed to evaluate the importance of these potential sublethal effects and the consequences of poor early nutrition to long-term fitness of sea turtles.

\section{ACKNOWLEDGMENTS}

We thank D. Hallman, R. Klinger, R. McCarty, M. Snover, and G. Zug for their advice on histological processing; L. Eschbach, B. Hall, D. Wheeler, T. Wronski, and J. Yonchek 
for laboratory assistance and evaluation of growth marks; J. Vonesh, C. Osenberg, and C. St Mary for advice and access to their image analysis system; "Equipa Tartaruga" at the Department of Oceanography and Fisheries (DOP), University of the Azores, "Projecto Tartaruga" from Madeira University, Madeira fishermen, and Direcção Regional de Pescas, Direcção de Seviços de Entrepostos Frigoríficos in Madeira for providing bone samples; J. Provancha for providing hatchling samples; E. Possardt for assistance with CITES importation; and P. Eliazar for technical assistance. We thank K. Kelley and the Electron Microscopy Core Laboratory, Biotechnology Program, University of Florida for assistance with the histological image. B. Bolker and M. Chaloupka provided invaluable statistical advice. The manuscript benefited from reviews by M. Chaloupka, M. Mangel, A. McCombe, N. Metcalfe, and J. Seminoff. This project was funded by Disney Wildlife Conservation Fund (to K. A. Bjorndal and A. B. Bolten), U.S. National Marine Fisheries Service (to K. A. Bjorndal and A. B. Bolten), and project Praxis/P/BIA/11310 from Fundação para a Ciência e a Tecnologia (to T. Dellinger). All work was conducted in compliance with the Institutional Animal Care and Use Committee, University of Florida.

\section{Literature Cited}

Ackerman, R. A. 1981. Growth and gas exchange of embryonic sea turtles (Chelonia, Caretta). Copeia 1981:757-765.

Bjorndal, K. A. 1997. Foraging ecology and nutrition of sea turtles. Pages 199-231 in P. L. Lutz and J. A. Musick, editors. The biology of sea turtles. CRC Press, Boca Raton, Florida, USA.

Bjorndal, K. A. In press. Roles of loggerhead sea turtles in marine ecosystems. In A. B. Bolten and B. E. Witherington, editors. Loggerhead sea turtles. Smithsonian Institution Press, Washington, D.C., USA.

Bjorndal, K. A., A. B. Bolten, and M. Y. Chaloupka. $2000 a$. Green turtle somatic growth model: evidence for density dependence. Ecological Applications 10:269-282.

Bjorndal, K. A., A. B. Bolten, and H. R. Martins. $2000 b$. Somatic growth model of juvenile loggerhead sea turtles Caretta caretta: duration of pelagic stage. Marine Ecology Progress Series 202:265-272.

Bolten, A. B. In press. Active swimmers-passive drifters: the oceanic juvenile stage of loggerheads in the Atlantic system. In A. B. Bolten and B. E. Witherington, editors. Loggerhead sea turtles. Smithsonian Institution Press, Washington, D.C., USA.

Bolten, A. B., K. A. Bjorndal, H. R. Martins, T. Dellinger, M. J. Biscoito, S. E. Encalada, and B. W. Bowen. 1998. Transatlantic developmental migrations of loggerhead sea turtles demonstrated by mtDNA sequence analysis. Ecological Applications 8:1-7.

Bolten, A. B., H. R. Martins, K. A. Bjorndal, and J. Gordon. 1993. Size distribution of pelagic-stage loggerhead sea turtles (Caretta caretta) in the waters around the Azores and Madeira. Arquipélago 11A:49-54.

Broekhuizen, N., W. S. C. Gurney, A. Jones, and A. D. Bryant. 1994. Modelling compensatory growth. Functional Ecology 8:770-782.

Castanet, J., H. Francillon-Vieillot, F. J. Meunier, and A. De Ricqles. 1993. Bone and individual aging. Pages 245-283 in B. K. Hall, editor. Bone, volume 7: Bone growth-B. CRC Press, Boca Raton, Florida, USA.

Chaloupka, M. Y. In press. Simulation modeling of loggerhead sea turtle population viability exposed to competing mortality risks in the southwestern Pacific region. In A. B. Bolten and B. E. Witherington, editors. Loggerhead sea turtles. Smithsonian Institution Press, Washington, D.C., USA.

Chaloupka, M. Y., and C. J. Limpus. 1997. Robust statistical modelling of hawksbill sea turtle growth rates (southern
Great Barrier Reef). Marine Ecology Progress Series 146: $1-8$.

Chaloupka, M. Y., and J. A. Musick. 1997. Age, growth, and population dynamics. Pages 233-276 in P. L. Lutz and J. A. Musick, editors. The biology of sea turtles. CRC Press, Boca Raton, Florida, USA.

Coles, W. C., J. A. Musick, and L. A. Williamson. 2001. Skeletochronology validation from an adult loggerhead (Caretta caretta). Copeia 2001:240-242.

Crouse, D. T., and N. B. Frazer. 1995. Population models and structure. Pages 601-603 in K. A. Bjorndal, editor. Biology and conservation of sea turtles, revised edition. Smithsonian Institution Press, Washington, D.C., USA.

Crowder, L. B., D. T. Crouse, S. S. Heppell, and T. H. Martin. 1994. Predicting the impact of excluder devices on loggerhead sea turtle populations. Ecological Applications 4: 437-445.

de Buffrénil, V., and J. Castanet. 2000. Age estimation by skeletochronology in the Nile monitor (Varanus niloticus), a highly exploited species. Journal of Herpetology 34:414424.

Grafen, A. 1988. On the uses of data on lifetime reproductive success. Pages 454-471 in T. H. Clutton-Brock, editor. Reproductive success: studies of individual variation in contrasting breeding systems. University of Chicago Press, Chicago, Illinois, USA.

Hagen, P. T., and T. J. Quinn, II. 1991. Long-term growth dynamics of young Pacific halibut: evidence of temperature-induced variation. Fisheries Research 11:283-306.

Hastie, T. J., and R. J. Tibshirani. 1990. Generalized additive models. Chapman and Hall, London, UK.

Hayward, R. S., D. B. Noltie, and N. Wang. 1997. Use of compensatory growth to double hybrid sunfish growth rates. Transactions of the American Fisheries Society 126: 316-322.

Heppell, S. S., D. T. Crouse, and L. B. Crowder. 1996. A model evaluation of headstarting as a management tool for long-lived turtles. Ecological Applications 6:556-565.

Heppell, S. S., L. B. Crowder, D. T. Crouse, S. P. Epperly, and N. B. Frazer. In press. Population models for Atlantic loggerheads: past, present and future. In A. B. Bolten and B. E. Witherington, editors. Loggerhead sea turtles. Smithsonian Institution Press, Washington, D.C., USA.

Heppell, S. S., L. B. Crowder, and T. R. Menzel. 1999. Life table analysis of long-lived marine species with implications for conservation and management. American Fisheries Society Symposium 23:137-148.

Hilton-Taylor, C., compiler. 2000. 2000 IUCN red list of threatened species. International Union for the Conservation of Nature, Gland, Switzerland.

Keinath, J. A., J. A. Musick, and R. A. Byles. 1987. Aspects of the biology of Virginia's sea turtles: 1979-1986. Virginia Journal of Science 38:329-336.

Klinger, R. C., and J. A. Musick. 1992. Annular growth layers in juvenile loggerhead turtles (Caretta caretta). Bulletin of Marine Science 51:224-230.

Lohmann, K. J., S. D. Cain, S. A. Dodge, and C. M. F. Lohmann. 2001. Regional magnetic fields as navigational markers for sea turtles. Science 294:364-366.

Lohmann, K. J., and C. M. F. Lohmann. In press. Orientation mechanisms of hatchling loggerheads. In A. B. Bolten and B. E. Witherington, editors. Loggerhead sea turtles. Smithsonian Institution Press, Washington, D.C., USA.

Madsen, T., and R. Shine. 2000. Silver spoons and snake body size: prey availability early in life influences longterm growth rates of free-ranging pythons. Journal of Animal Ecology 69:952-958.

Mangel, M. In press. Environment and life span: a precis. Population and Development Review. 
McCauley, S. J., and K. A. Bjorndal. 1999. Conservation implications of dietary dilution from debris ingestion: sublethal effects in post-hatchling loggerhead sea turtles. Conservation Biology 13:925-929.

Metcalfe, N. B., and P. Monaghan. 2001. Compensation for a bad start: grow now, pay later? Trends in Ecology and Evolution 16:254-260.

Mrosovsky, N., and J. Provancha. 1992. Sex ratio of hatchling loggerhead sea turtles: data and estimates from a 5year study. Canadian Journal of Zoology 70:530-538.

Musick, J. A., and C. J. Limpus. 1997. Habitat utilization and migration in juvenile sea turtles. Pages 137-163 in P. L. Lutz and J. A. Musick, editors. Biology of sea turtles. CRC Press, Boca Raton, Florida, USA.

National Research Council. 1990. Decline of the sea turtles: causes and prevention. National Academy Press, Washington, D.C., USA.

Nicieza, A. G., and F. Braña. 1993. Compensatory growth and optimum size in one-year-old smolts of Atlantic salmon (Salmo salar). Pages 225-237 in R. J. Gibson and R. E. Cutting, editors. Production of juvenile Atlantic salmon, Salmo salar, in natural waters. Canadian Special Publication of Fisheries and Aquatic Sciences, number 118. Department of Fisheries and Oceans, Ottawa, Ontario, Canada.

Nicieza, A. G., and N. B. Metcalfe. 1997. Growth compensation in juvenile Atlantic salmon: responses to depressed temperature and food availability. Ecology 78:2385-2400.

Parham, J. F., and G. R. Zug. 1997. Age and growth of loggerhead sea turtles (Caretta caretta) of coastal Georgia: an assessment of skeletochronological age-estimates. Bulletin of Marine Science 61:287-304.

Ricker, W. E. 1992. Back-calculation of fish lengths based on proportionality between scale and length increments. Canadian Journal of Fisheries and Aquatic Sciences 49 : 1018-1026.
Salmon, M., and J. Wyneken. 1987. Orientation and swimming behavior of hatchling loggerhead turtles (Caretta caretta L.) during their offshore migration. Journal of Experimental Marine Biology and Ecology 109:137-153.

Whalen, K. G., and G. W. LaBar. 1998. Survival and growth of unfed and fed Atlantic salmon fry stocked in a Vermont tributary of the Connecticut River. North American Journal of Fisheries Management 18:931-935.

Whitledge, G. W., R. S. Hayward, D. B. Noltie, and N. Wang. 1998. Testing bioenergetics models under feeding regimes that elicit compensatory growth. Transactions of the American Fisheries Society 127:740-746.

Wilson, P. N., and D. F. Osbourn. 1960. Compensatory growth after undernutrition in mammals and birds. Biology Reviews of the Cambridge Philosophical Society 37:324363.

Witherington, B. E. 1991. Orientation of hatchling loggerhead turtles at sea off artificially lighted and dark beaches. Journal of Experimental Marine Biology and Ecology 149: $1-11$.

Witherington, B. E. 2002. Ecology of neonate loggerhead turtles inhabiting lines of downwelling near a Gulf Stream front. Marine Biology 140:843-853.

Wyneken, J. 1997. Sea turtle locomotion: mechanisms, behavior, and energetics. Pages 165-198 in P. L. Lutz and J. A. Musick, editors. The biology of sea turtles. CRC Press, Boca Raton, Florida, USA.

Zar, J. H. 1984. Biostatistical analysis. Second edition. Prentice-Hall, Englewood Cliffs, New Jersey, USA.

Zug, G. R., G. H. Balazs, and J. A. Wetherall. 1995. Growth in juvenile loggerhead seaturtles (Caretta caretta) in the North Pacific pelagic habitat. Copeia 1995:484-487.

Zug, G. R., A. H. Wynn, and C. Ruckdeschel. 1986. Age determination of loggerhead sea turtles, Caretta caretta, by incremental growth marks in the skeleton. Smithsonian Contributions to Zoology 427:1-34. 